\title{
A comparative study between sinotomy with or without marsupialization versus sinotomy and primary closure with or without drain in the management of pilonidal sinus Mahmoud Mohamed Mahran*, Mahmoud Salah Shehata, Akram Mohamed Mohamed Abd- Elwahab \\ Department of General Surgery, Faculty of Medicine, Al-Azhar University, Cairo, Corresponding author: Akram Mohamed Mohamed Abd-Elwahab, email: hero3starss@gmail.com
}

\begin{abstract}
Background: pilonidal sinus (PNS) is a common condition. Although many methods for treatment are available, there is no consensus on the optimal treatment.

Aim of the study: The aim of the work was to compare the outcome of sinotomy procedure with or without marsupialization versus sinectomy and primary closure with or without drain in the management of pilonidal sinus as regards operative times, postoperative complications, and time of healing and return of work.

Patients and Methods: This is a comparative randomized comparative study. Sixteen patients undergoing surgery for primary PNS were enrolled. The patients were randomized into four groups. Each group included 15 patients. Group A underwent sinotomy without marsupialization; group B underwent sinotomy with marsupialization; group $\mathrm{C}$ underwent limited excision and primary closure with a drain and group $\mathrm{D}$ underwent the same procedure as group $\mathrm{C}$ but without drain. Each patient was followed up for 6 months.

Results: Significantly short operative time was recorded in group B. Postoperative wound complications occurred in $3.2 \%$ of patients in group $\mathrm{A}$, in $1.7 \%$ of patients in $\mathrm{B}$, in $7.4 \%$ of patients in group $\mathrm{C}$ and in $4.2 \%$ of patients in group D. Recurrence rate was a slightly higher in group C but with no statistical significance.

Conclusion: The sinotomy with marsupialization for treatment of PNS is superior to excision with primary closure either with or without a drain and sinotomy without marsupialization.
\end{abstract}

Keywords: sinectomy, pilonidal sinus, primary closure, sinotomy

\section{Introduction:}

Pilonidal sinus [PNS] is a common infectious process which occurs in buttocks and sacral area, involves a wide range of symptoms ranges from an asymptomatic sinus to acute and chronic sinus track ${ }^{(1)}$.

The etiology of this disease is not fully understood, some are believed to be congenital in origin and some considered being an acquired disease. The reason of this condition can be seen in folds between the fingers of hairdressers, shepherds and dog trainers which can be due to penetration of the hair as a foreign body and cause reactions in the subcutaneous tissue $^{(2)}$.

Risk factors include adiposity, sedentary lifestyle, local irritation, trauma, insufficient body hygiene, excessive hair and perspiration (3).

Many techniques have been advocated for the surgical management of PNS. They are classified basically into two groups, total excision of the sinus, followed by either leaving the wound open for secondary healing or its primary closure with techniques ranging from simple suturing to the numerous complex methods for coverage.

However, recurrence is still an important problem and its optimal management remains controversial $^{(4)}$.

The quality of life of patients who underwent sinotomy with marsupialization was much better than sinotomy without marsupialization and sinectomy with primary closure either with drain or not in terms of time to comfortable walking, sitting on the toilet and healing time to return to work on the first and fifth day postoperatively. This was in accordance with many studies that showed that the sinotomy technique minimized the time away from work, deviation from normal activities and costs ${ }^{(5)}$.

The ideal approach for the management of PNS should be simple, cause minimal pain, have best chance for success and least recurrence rate with low risk for complications, avoid general anesthesia, require minimal wound care and ensure minimal inconvenience for the patient with rapid return to normal activity ${ }^{(6)}$.

Aim of the study: 
The aim of the work is to compare the outcome of sinotomy procedure with or without marsupialization versus sinectomy and primary closure with or without drain in the management of pilonidal sinus as regards operative times, postoperative complications, and time of healing and return of work.

\section{Patients and methods:}

This is comparative randomized study was conducted at Department of General Surgery, Imbaba General Hospital, after obtaining approval from local ethical committee and after fully informed written consent signed by the patient.

This study carried out on 60 consecutive patients with primary non recurrent sacrococcygeal pilonidal sinus from $1 / 12 / 2017$ to $1 / 7 / 2018$. Age, sex, presentation, number of sinus pits, midline or lateral pits, treatment, complications, inpatient stay and postoperative outcome were recorded.

The patients were randomized into four groups:

Group A: consisted of 15 patients managed by sinotomy without marsupialization.

Group B: consisted of 15 patients managed by sinotomy with marsupialization.

Group C: consisted of 15 patients managed by sinectomy and primary closure using a drain.

Group D: consisted of 15 patients managed bysinectomyand primary closure without drain.

Inclusion criteria

1. Patients with chronic non-infected nonrecurrent sinus. Preoperative work up

All Patients were subjected to:

$\begin{array}{ll}\text { 1. } & \text { History Taking } \\ \text { 2. } & \text { Clinical Examination } \\ \text { 3. } & \text { Laboratory investigations: } \\ \text { 1. } & \text { Complete blood count. } \\ \text { 2. } & \text { Liver function tests. } \\ \text { 3. } & \text { Kidney function tests. } \\ \text { 4. } & \text { Random blood sugar. }\end{array}$

\section{Preoperative care}

A patient record form was prepared, and patients' age, sex, duration of symptoms, preoperative antibiotic use, previous treatments, length of hospital stay, return to work, complications such as wound breakdown and infection and wound care time were recorded. All patients were admitted to hospital the day before surgery and operated under spinal anesthesia.

\section{Surgical techniques:}

\section{General Consideration}

Patients were prepared preoperatively with intravenous $500 \mathrm{mg}$ metronidazole and $1 \mathrm{~g}$ ceftriaxone $20 \mathrm{~min}$ before the procedure. Evacuation enemas were done a few hours before the procedure and shaving of the operation area on table. Spinal anesthesia was adopted in most of the cases, but general anesthesia was also used in some cases. During the operation, the patient was placed in the prone position with the pelvis elevated with a pillow. An adhesive tape was used to strap the buttocks apart for proper exposure of the sinus area which was disinfected with $10 \%$ povidone-iodine.

\section{Group A (sinotomy without marsupialization)}

After identification of the main sinus orifice, it was probed and the main track was laid open. Any cysts or hair tufts were removed. The whole cavity was then washed with $\mathrm{H}_{2} \mathrm{O}_{2}$ and $10 \%$ povidone-iodine and irrigated with saline. Meticulous hemostasis and packing with good compression was achieved.

The wound was dressed every day for 3 days.

Thereafter, healing-promoting local applicants were used until complete healing was achieved.

\section{Group B (sinotomy with marsupialization)}

Group (B) patients underwent the same procedure

as those of group (A) but after laying open, the walls of the track were sutured with the skin outside.Removal of sutures was done at 10-14 days [figure 1].

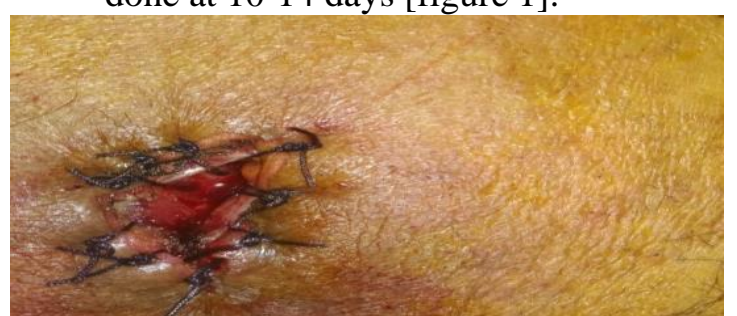

Figure (1): Sinotomy with marsupialization

Group C (sinectomy and primary closure using a drain)

After identification of the main sinus orifice, the main and side tracks were excised with minimal tissue removal to achieve a tensionfree closure. Thus, there was no need to 
reach the sacral fascia. Then a suction drain was put to be removed within $48-72 \mathrm{~h}$. After that, skin closure was done using prolene $3 / 0$ or $4 / 0$ simple interrupted sutures followed by compression dressing which was changed after 48-72 $\mathrm{h}$ and then every day [Figure 2-3].

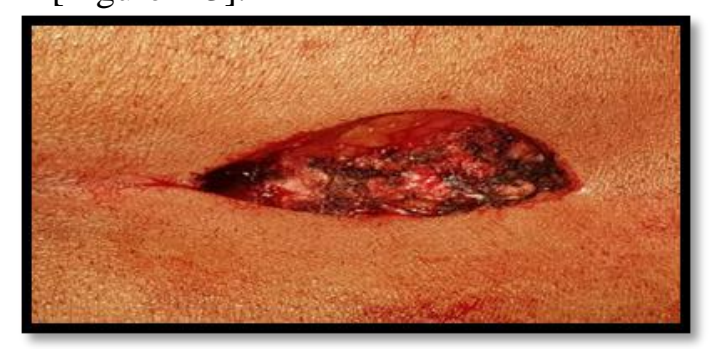

Figure (2): Tracks were excised with minimal tissue removal.

Figure (3): wound closure.

\section{Group D (sinectomy and primary closure without drain)}

As pervious procedure but after excision of the sinus, tension sutures with prolene (1) are applied to the wound to approximate the edges and prevention gaped wound.

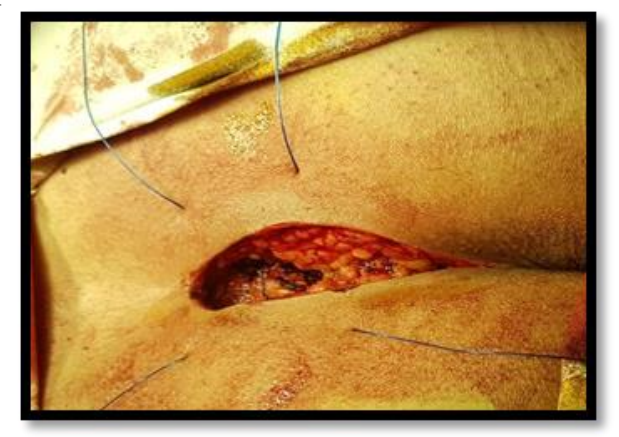

Figure (4): Tension suture Post operative care
Antibiotics and analgesics were needed for groups (C) and (D) postoperatively for 5 days followed by administration of analgesics on demand, whereas analgesics were used on demand in patients in group (A) and (B) with no need for antibiotics.

All patients were followed every other day for one week, then weekly until complete healing, then monthly for six months. The drain was removed from group (C) patients within 48-72 $\mathrm{h}$ postoperatively to make sure that there were no wound complications.

Removal of sutures was done at 2-3 weeks. If there were any wound complications, sutures were removed and the wound was dealt with as the open method until complete healing. If no healing occurred despite careful wound dressing, this was considered as healing failure. Disease recurrence was considered after the disease free interval following complete healing

\section{Results: \\ Patients and Methods:}

The present study was carried out on 60 patients with pilonidal sinus. There were 45 males and 15 females with male to female ratio 3:1. Each group included 15 patients.

Mean age of patients in group (A) was (24.7 year) ranging from 16-35 year and the mean in group B is (24.4year) ranging from 17-30 year. Male sex predominance was recorded in both groups.

There was no significant difference between the four groups as regards age but was significant as regards male sex predominance as shown in table (1) and figure (5).

Table (1): Demography of the patients

\begin{tabular}{|cccccccc||}
\hline Demography & Group $(A)$ & Group $(B)$ & Group $(C)$ & Group $(D)$ & Total number & P value & Significant \\
Age & 24.7 & 24.4 & 28.6 & 26.7 & & 0.854 & N.S \\
Mean & $16-35$ & $17-30$ & $20-35$ & $18-33$ & & & \\
Range & 11 & 12 & 10 & 12 & $45(75 \%)$ & 0.877 & N.S \\
Sex [n (\%)] & 4 & 3 & 5 & 3 & $15(25 \%)$ & & \\
Male & & & & & & & \\
Female & & & & & & &
\end{tabular}


A comparative study between sinotomy with or without marsupialization...

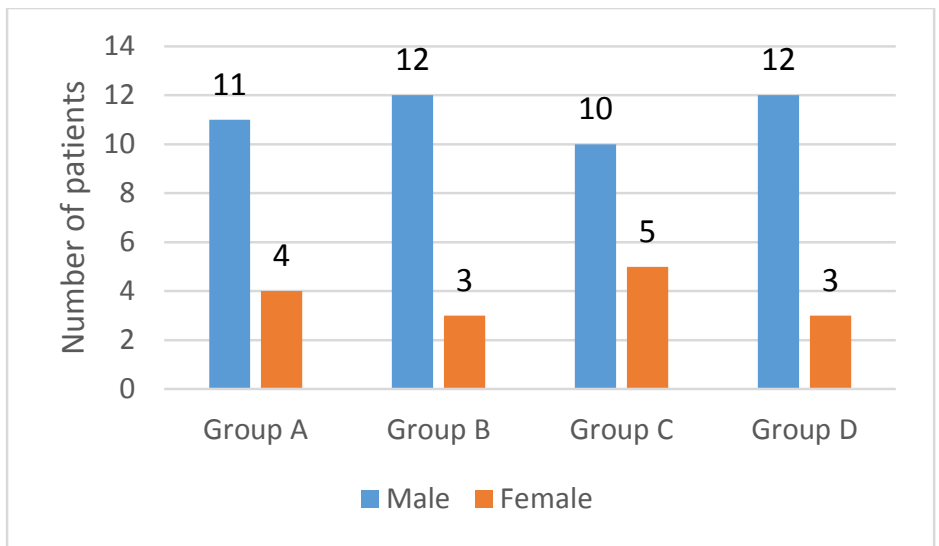

Figure (5): Sex distribution.

\section{Clinical features:}

Clinical features varied from multiple sinuses, single sinus to sacrococcygeal swelling and sinus (es). However, there was no significant difference between the four groups as regards preoperative presentations.

\section{Operative time:}

It was found that the mean operative time was significantly shorter in group (B) than the other three groups as shown in table (2) and figure (6).

Table (2): Operative time.

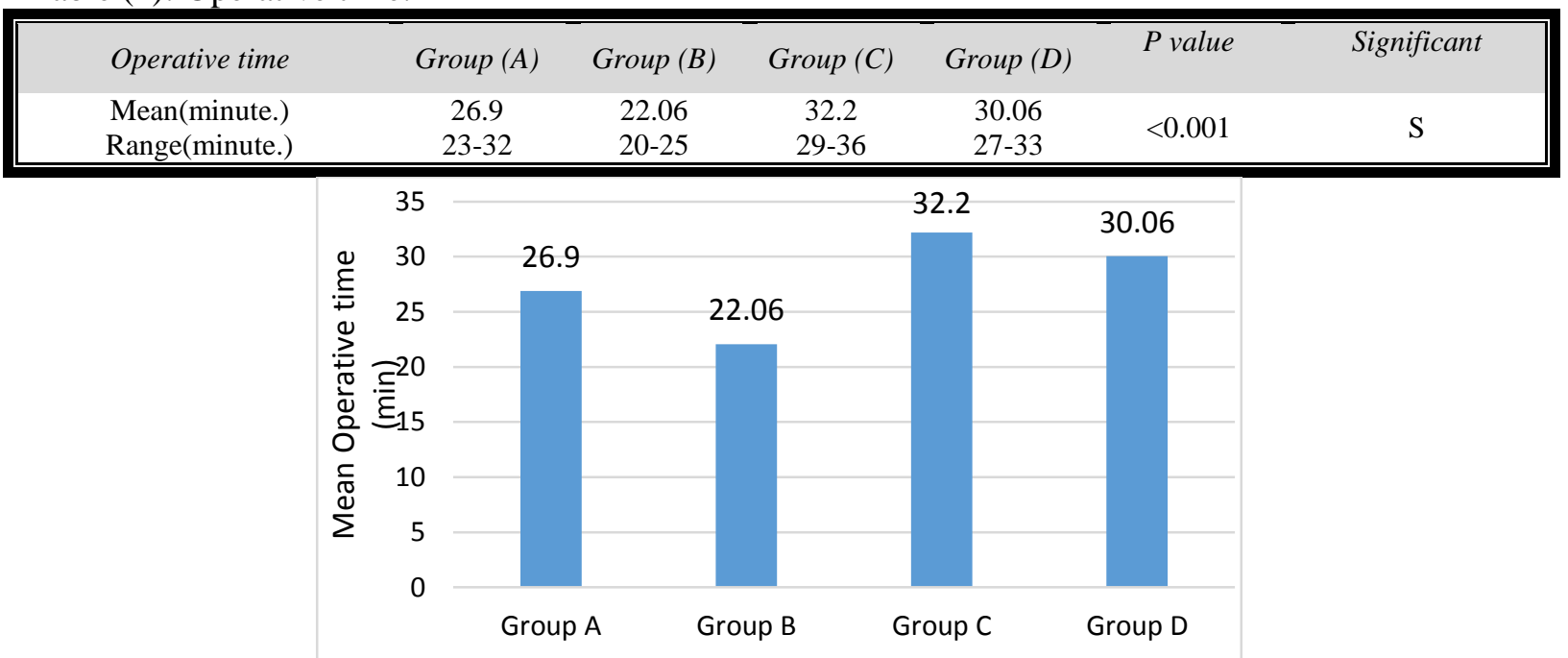

Figure (6): Mean Operative time (minute).

\section{Postoperative complications:}

Over all postoperative complications were present in fifteen patients. Three patients in group (A), One patient in group (B), seven patients in group (C) and four patients in group (D) as shown in table (3) and figure (7).

Table (3): Postoperative complications.

\begin{tabular}{|cccccc|}
\hline Postoperative complications & $\begin{array}{c}\text { Group } \\
(A)\end{array}$ & $\begin{array}{c}\text { Group } \\
(B)\end{array}$ & $\begin{array}{c}\text { Group } \\
(C)\end{array}$ & Group $(D) \begin{array}{c}\text { Total } \\
\text { number }\end{array}$ \\
Overall postoperative & 3 & 1 & 7 & 4 & 15 \\
complications & 1 & 0 & 0 & 0 & 1 \\
Postoperative hemorrhage & 0 & 0 & 1 & 0 & 1 \\
Hematoma & 0 & 0 & 2 & 3 & 5 \\
Discharge & 2 & 1 & 4 & 1 & 8 \\
Wound infection & &
\end{tabular}




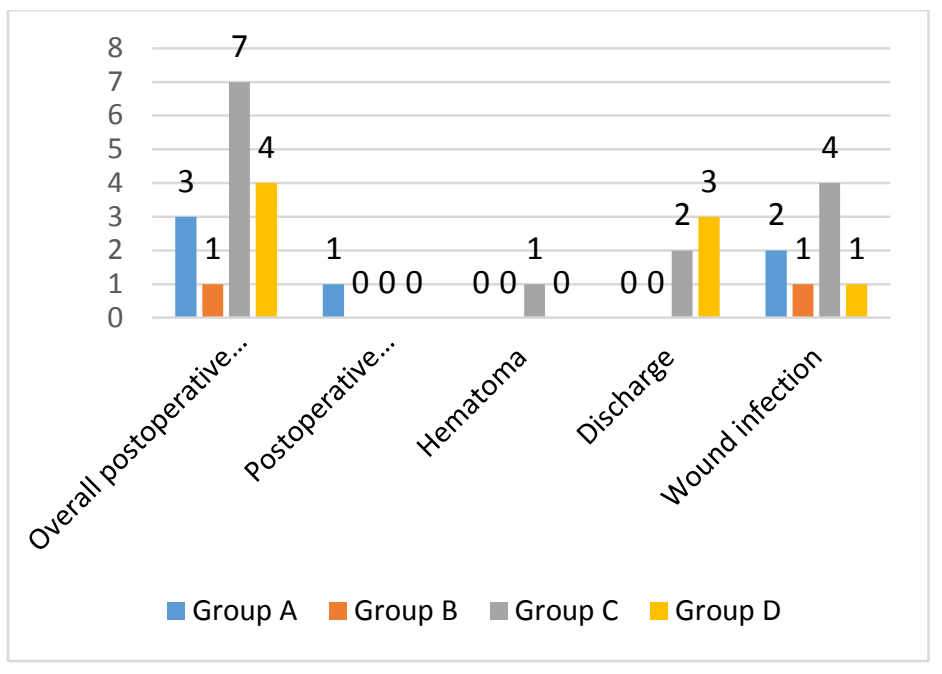

\section{Hospital stay, time of healing and duration of work-off:}

Figure (7): Postoperative complications.

The mean hospital stay was significantly shorter in group (B) compared with the other three groups. Healing time is generally longer in techniques involving secondary healing than in techniques with primary closure in the absence of wound complications. The mean healing time was longer in groups (A) and (B) (30.81 and 30.5 days) than in groups (C) and (D) (17.27and 17.74 days). The mean time before return to work was significantly shorter in group (B) (3.89 days) compared with groups (A), (C) and (D) ( 4.12, 19.82 and 19.68 days respectively). Although the healing time is longer following the sinotomy technique, the minimal wound care required after the first postoperative week did not undermine the quality of life of the patients as shown in table (4).

Table (4): Hospital stay, time of healing and work-off period.

\begin{tabular}{|c|c|c|c|c|c|c|}
\hline Convalescence & Group (A) & Group $(B)$ & Group $(C)$ & $\operatorname{Group}(D)$ & $\overline{P \text { Pvalue }}$ & Significant \\
\hline Hospital stay (days) & 0.23 & 0.20 & 2.09 & 1.5 & $<0.001$ & S \\
\hline Time of healing (days) & 30.8 & 30.5 & 17.27 & 17.74 & $<0.001$ & $S$ \\
\hline Work-off period (days) & 4.12 & 3.98 & 19.82 & 19.68 & $<0.001$ & S \\
\hline
\end{tabular}

\section{Long-term outcome:}

Scar pain and numbness disappeared after 6 months postoperatively in all groups. There was a significant difference between the four groups as regards scar pain, numbness and recurrence rate as shown in table (5) and figure (8).

Table (5): Long-term outcome.

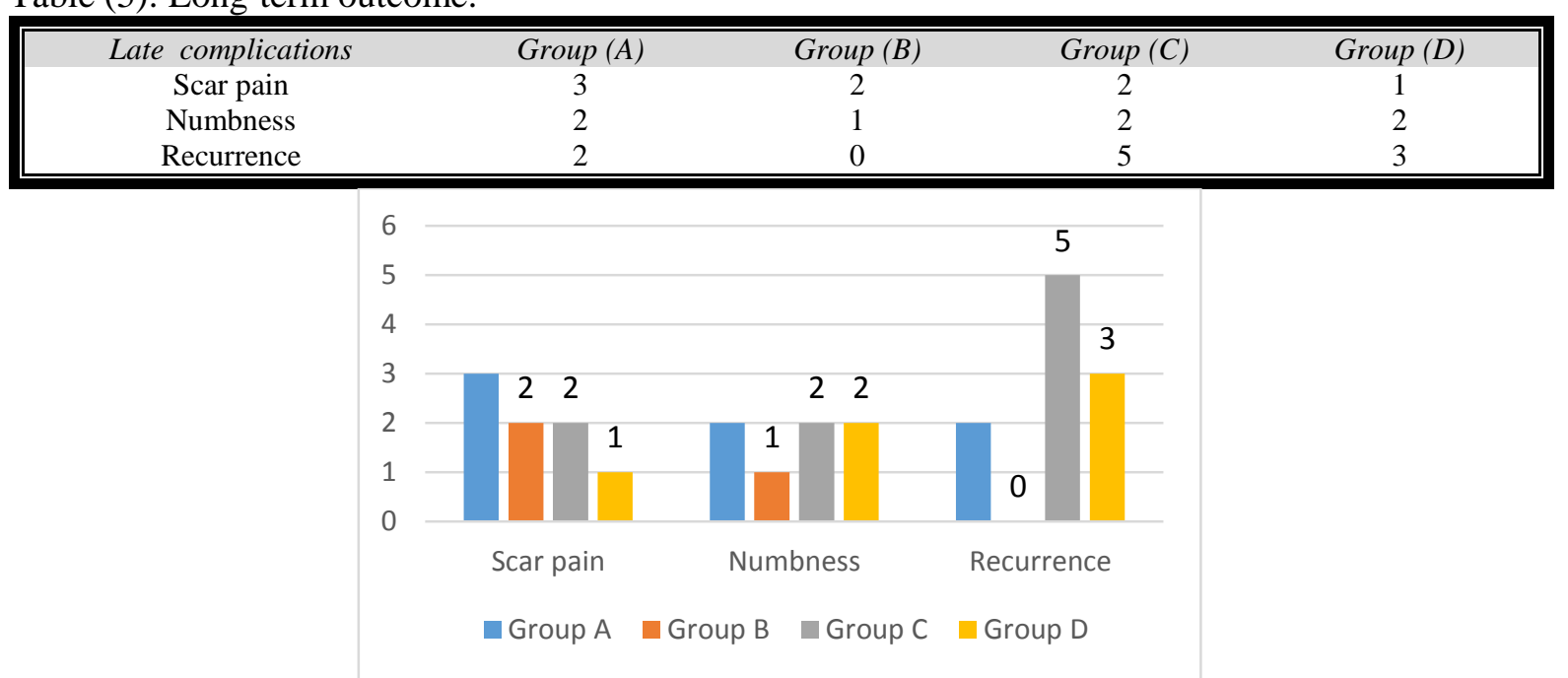

Figure (8): Long-term outcome. 


\section{Discussion:}

Pilonidal sinus remains a problem for the surgeon and nuisance to the patients. Pilonidal sinus disease is an acquired condition usually seen in young adults and carries high post-operative morbidity and patient discomfort. Complicated pilonidal surgical wounds are associated with considerable morbidity including chronic sacral wound, loss of work time and lifestyle limitation ${ }^{(7)}$.

A deep natal cleft is a favorable environment for sweating, maceration, bacterial contamination and penetration of hair, so for treatment and prevention, these causative factors must be eliminated ${ }^{(8)}$.

Many techniques have been advocated for the surgical management of PNS. They are classified basically into two groups, total excision of the sinus followed by either leaving the wound open for secondary healing or its primary closure with techniques ranging from simple suturing to the numerous complex methods for coverage. However, recurrence is still an important problem and its optimal management remains controversial ${ }^{(4)}$.

In the present study, the spectrum of postoperative wound complications varies according to the type of surgery. Leaving the wound open may result in early bridging or chronic non healing, whereas the primary closure technique increases the risks for hematoma, seroma, and infection. Complications developed in (2\%) patients who underwent sinotomy with marsupialization and (5\%) patients who underwent sinotomy without marsupialization compared with $(74 \%)$ patients who underwent primary closure either with or without drain. The reported complication rates following excision with primary closure vary markedly.

Akinci et al. ${ }^{(9)}$ in their series of 112 patients with PNS who treated surgically by using asymmetric excision and primary closure with suction drain; reported two wound infections, two wound breakdowns, three cases with collections and one recurrence. The cases were followed-up for 2 years. The average healing time was 13.2 days. They concluded that the procedure was simple, the complications and recurrences were very low and it was excellent in the surgical treatment of uncomplicated pilonidal sinus disease.

In contrast, Perruchoud et al. (10) compared excision and open granulation with excision and primary closure and found primary healing failure rate of $9 \%$ following primary closure.

Adriano et al. ${ }^{(11)}$ studied 103 patients with non-recurrent quiescent chronic discharging, 53 patients had excision and primary closure with drainage in group (A) and 50 patients drainage was omitted in group (B). Minor wound dehiscence occurred in 3 patients in group (A) while in group (B) 6 patients had wound hematoma, 17 patients had wound infection and 13 patients had minor wound dehiscence. No complete dehiscence of the wound was observed in patients in group (A) while it was observed in 8 patients in group (B). Complete healing was fastest in patients in group (A). They reported that excision with primary closure and wound drainage was a simple and effective procedure in the surgical treatment of uncomplicated pilonidal sinus.

Serour et al. ${ }^{(12)}$ studied 34 adolescent patients who underwent excision with primary closure and closed suction drainage and reported that primary healing with no postoperative complications occurred in 30 patients $(88.2 \%)$; 1 underwent partial opening of the wound because of rupture of the drainage tube during its removal. Postoperative wound infections requiring incision, drainage, and layopen occurred in 3 cases $(9.1 \%)$. No recurrence was found at 12-month follow-up. They concluded that excision with primary closure and closed suction drainage was a simple and effective method of treatment of uncomplicated pilonidal sinus in adolescents.

In our study, single doses of ceftriaxone and metronidazole were used preoperatively in all patients in the four groups to achieve standardization, whereas antibiotics were used only in groups (C) and (D) (wound closure). Only one patient had wound infection in patients who underwent sinotomy with marsupialization (group B), whereas five patients had wound infection following excision with primary closure groups $(\mathrm{C})$ and (D) and two patients had wound infection following sinotomy without marsupialization (group A), supporting the hypothesis that type of surgical intervention may affect the rate of wound infection more than the use of antibiotic prophylaxis. The sinotomy with marsupialization technique has an advantage of being simple with short operative time as recorded in our study compared with the other three groups. 
Prophylactic antibiotic use in the surgical treatment of PNS is still controversial. Some authors do not recommend antibiotics in view of the fact that preoperative bacterial isolates, usually anaerobes, in chronic PNSs do not affect the complication rate because bacterial isolates from infected wounds are mostly aerobes ${ }^{(13)}$.

Other studies concluded that prophylactic antibiotics seem to be unnecessary in patients undergoing sinotomy technique while prophylaxis may be helpful to prevent infectious complications during excision with primary closure ${ }^{(14)}$.

In our study, the mean hospital stay was significantly shorter in group (A) and (B) compared with groups (C) and (D). Healing time is generally longer in techniques involving secondary healing than in techniques with primary closure in the absence of wound complications. The mean healing time was longer in groups (A) and (B) than in groups (C) and (D) similar to many previous reports. The patients undergoing sinotomy with marsupialization were encouraged to return to work as early as possible. The mean time before return to work was significantly shorter in this group compared with the other three groups. Although the healing time is longer following sinotomy with marsupialization, the minimal wound care required after the first postoperative week did not undermine the quality of life of the patients.

Perruchoud et al. ${ }^{(10)}$ who reported an average healing time of 72 days and an average time before return to work of 38 days in patients who had undergone total excision and open granulation compared with 23 and 21 days respectively after excision and primary closure.

Similarly, Fuzun et al. ${ }^{(\mathbf{1 5})}$ reported that the time to return to work was significantly shorter following total excision with primary closure compared with that after total excision and secondary healing. excision

The mean duration of hospital stay in primary closure techniques reported in previous studies was $4-5$ days ${ }^{(16)}$.

In the present study, the use of suction drainage in patients in group (C) showed a recurrence rate that was higher compared with the other three groups.

The use of suction drains following excision with primary closure is still controversial. Serour et al. ${ }^{(12)}$ recommended routine use of suction drainage with primary closure

The quality of life of the patients who underwent sinotomy with marsupialization was much better than sinotomy without marsupialization and sinectomy with primary closure either with drain or not in terms of time to comfortable walking, sitting, sitting on the toilet and healing, time to return to work on the first and fifth day postoperatively. This was in accordance with many studies that showed that the sinotomy technique minimized the time away from work, deviation from normal activities and costs ${ }^{(5)}$.

The ideal approach for the management of PNS should be simple, cause minimal pain, have best chance for success and least recurrence rate with low risk for complications, avoid general anesthesia, require minimal wound care, and ensure minimal inconvenience for the patient with rapid return to normal activity ${ }^{(6)}$.

\section{Conclusions:}

The sinotomy with marsupialization for treatment of PNS is superior to excision with primary closure either with or without a drain and sinotomy without marsupialization with respect to operative time, hospital stay, comfort in walking, sitting and return to work.

\section{References:}

1. De Parades V, Bouchard D, Janier M, Berger A(2013): Pilonidal sinus disease. J Visc Surg. , 150(4):237-47.

2. Bradley L(2010): Pilonidal sinus disease, a review, Part one. J Wound Care,19(11):504508

3. Bendewald FP, Cima RR(2007): Pilonidal disease. Clin Colon Rectal Surg .,20:86-95

4. Gencosmanoglu R, Inceoglu $R$ (2005): Modified lay-open (incision, curettage,partial lateral wall excision and marsupialization) versus total excisionwith primary closure in the treatment of chronic sacrococcygealpilonidalsinus: a prospective, randomized clinical trial with a complete twoyear follow-up. Int J Colorectal Dis., 20:415422

5. Spyridakis M, Christodoulidis G, Chatzitheofilou C et al. (2009): The role of the platelet-rich plasma in accelerating the woundhealing process and recovery in patients being operated for pilonidal sinus disease: 
preliminary results. World J Surg., 33(8):17649.

6. Hull TL (2002);Pilonidal disease. SurgClin North Am., 1169(6):82-85

7. Surrel JA (1994): Pilonidal disease. SurgClin North Am., 74:1309-15.

8. Eryilmaz R, Sahin M, Alimoglu O( 2003): Surgical treatment of sacrococcygeal pilonidal sinus with the limberg transposition flap. Surgery, 134:745-9.

9-Akinci OF, Kurt M, Terzi A, Atak I, Subasi IE, Akbilgic O.( 2009): Natal cleft deeper in patients with pilonidal sinus: implications for choice of surgical procedure. Dis Colon Rectum. 52(5):1000-2.

10.Perruchoud C, Vuilleumier H, Givel JC( 2002): Pilonidal sinus: how to choosebetween excision and open granulation versus excision and primaryclosure? Study of a series of 141 patients operated on from 1991 to1995. Swiss Surg., 8:255-25

11.Adriano T, Gianluca M. Marco B, Vittorio F, Michelangelo M, Andrea D, Lidia C.( 2008): Outcome of chronic pilonidal disease treatment after ambulatory plain midline excision and primary suture. Am J Surg; 196:28-33.
12.Serour F, Somekh E, Krutman B( 2002): Excision with primary closure and suction drainage for pilonidal sinus in adolescent patient. Pediatrics SurgInt., 18:159-61.

13.Sondenaa K, Diab R, Nesvik I, Gullaksen F. P, Kristiansen R. M, Saebo A et al.( 2002): Influence of failure of primary wound healing on subsequent recurrence of pilonidal sinus. Combined Prospective study and randomized controlled trial. Eur J Surg.,614(11):614-618.

14. Bunoza D, Miocinović M, Horzić M( 2001): The prevalence of anaerobic infection inpilonidal sinus of the sacrococcygeal region and its effect on thecomplications. Acta Med Croatica,55:87-90.

15.Fuzun M, Bakir H, Soylu M, Tansug T, Kaymak E, Harmancioglu O.( 1991): Whichtechnique for treatment of pilonidal sinus - open or closed? Dis ColonRectum; 37:1148-1150

16.Abu Galala KH, Salam IM, Abu Samaan KR et al.( 1999): Treatment of pilonidal sinus by primary closure with a transposed rhomboid flap compared with deep suturing: a prospective randomisedclinicaltrial. EurJSurg.,165(5):46872. 